\title{
Modelling of small river deltas: the dependence of morphology on grain size and discharge
}

\author{
Piotr WITEK ${ }^{1, *}$, Leszek CZECHOWSKI ${ }^{1}$ and Katarzyna MISIURA ${ }^{1}$ \\ 1 University of Warsaw, Institute of Geophysics, Żwirki i Wigury 93, 02-089 Warszawa, Poland
}

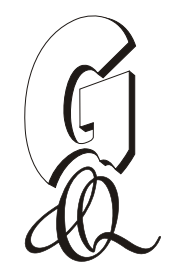

Witek, P., Czechowski, L., Misiura, K., 2016. Modelling of small river deltas: the dependence of morphology on grain size and discharge. Geological Quarterly, 60 (4): 975-980, doi: 10.7306/gq.1324

\begin{abstract}
We studied the dependence of the morphology of small river deltas on the grain size, the total discharge, and the slope of the deposits. We use Computational Fluid Dynamics (CFD) methods of numerical modelling. For all models we used the same initial geometry of the river valley and a portion of the lake. Our simulations show the expected dependence of the shape of our simulated small deltas on the grain size. Moreover, we find that the final type of delta could be characterized by the average slope in the region close to the delta front.
\end{abstract}

Key words: hydrology, sedimentology, river deltas, numerical modelling.

INTRODUCTION

The processes of erosion, transport, and sedimentation occur in all natural rivers. The transported material is deposited downstream; the largest deposits are formed where the flow fades - in particular in the standing body of liquid. The morphology and evolution of sedimentary deposits depend on several factors, such as the size of sediment grains, discharge, slope, waves, and other processes in the river as well as in the basin.

Deltas and alluvial fans take different shapes depending on the relative importance of river processes, waves, and tides (Galloway, 1975). Another factor important for the shape and development of river deltas is the grain size (Orton and Reading, 1993). The sediments may consist of different mixtures of silt, sand or gravel, depending on the terrain properties such as erodibility, the availability of loose sediments, and distance from the source, because granular material is naturally sorted to a certain degree by a flowing river. The role of grain size is a result of the dependence of the settling velocity and the drag force on the diameter of sediment particles. Sediment grains of different sizes travel in different ways: small grains are transported mostly in suspension, while gravel-sized grains are transported as a bed load. Of course, the mode of transport depends also on the discharge, slope, density of sediments, and other factors. This leads to different mixing behaviours at the river mouth. Coarse sand and gravel tend to build fan deltas with steep gradients of the delta plain (usually $>5 \mathrm{~m} \mathrm{~km}^{-1}$ ), whereas

* Corresponding author, e-mail: ppwit@igf.fuw.edu.pl

Received: May 11, 2016; accepted: October 12, 2016; first published online: November 2, 2016 mud and fine sand are responsible for the creation of elongate ("bird's foot delta") and lobate deltas with lower slopes ( $S<5 \mathrm{~m} \mathrm{~km}^{-1}$; Orton and Reading, 1993).

The formation and evolution of river deltas on the Earth has been studied extensively, in the field as well as in the laboratory and using computer simulations (see e.g., Edmonds and Slingerland, 2007). The areal extent of the delta plain varies by orders of magnitude, from $>450,000 \mathrm{~km}^{2}$ for the Amazon to $<1 \mathrm{~km}^{2}$, and delta plains with surface area $<50 \mathrm{~km}^{2}$ can be considered "small" (Orton and Reading, 1993). The structure that forms in our simulations has an area of $<1 \mathrm{~km}^{2}$. However, most of the research is concentrated on large deltas, like the Mississippi delta, because of their importance to humans. Small fans and deltas are much more common, yet less explored. Space probes have discovered ancient river deltas on Mars and current fluvial activity on Titan, a moon of Saturn (see Kereszturi, 2010; Misiura and Czechowski, 2015; Witek and Czechowski, 2015). Most of the Martian palaeodeltas are closed-basin deltas formed in crater lakes. Despite the observational bias towards large and highly-pronounced landforms, most of the known deltas on Mars are $<100 \mathrm{~km}^{2}$ in size (Irwin et al., 2005). Our model can and will be used for comparison with processes on these planetary objects. While Reduced Complexity Models (RCM; Kondolf and Piégay, 2016) have proven to be capable of giving many results compatible with the field observations (e.g., Seybold et al., 2007; Geleynse et al., 2010), we decided to use the CFD (Computational Fluid Dynamics) model based on physical equations for dynamics of flow. According to our best knowledge our paper is the first to systematically compare the classification of river-dominated deltas using numerical modelling. Of course, we are aware of other factors important for the evolution of some deltas, but as this is the first approach of its kind it is difficult to include all possible situations. Note also that:

- the subsidence is usually negligible for the considered time scales (Anderson and Anderson, 2010); 
- basin subsidence is important only for large masses of accumulated sediments or in specific settings (Anderson and Anderson, 2010) - for places such as the Polish lowlands it is negligible;

- tides are generally negligible for all lakes - the amplitude is 1-2 cm in Great Lakes (Trebitz, 2006) - and most of the intercontinental seas. For example, in the Baltic Sea the tidal height may reach $18 \mathrm{~cm}$ at the head of the Gulf of Finland, but it is much smaller in other parts of the sea (Medvedev et al., 2013);

- sea currents could be important for some river deltas but not for deltas in typical lakes (including coastal lakes and lagoons such as the Vistula Lagoon in Poland);

- the role of waves in a typical Polish lake (i.e. medium-sized) is limited;

- note also the low velocity of rivers in lowlands and usually well-sorted grains. Therefore we believe that the results of our model could be applied to most of the present river deltas in lakes in the lowlands of Poland;

- we concentrate here on the results of numerical modelling because other approaches are discussed in numerous other papers;

- in our next research we will include other distributions of grain sizes and initially existing landforms.

\section{MODEL AND ITS PARAMETERS}

The present research uses the same method as described in our previous paper (Witek and Czechowski, 2015). We use the same simplified initial geometry of the river channel and part of the lake (see Fig. 1). The lake has a constant surface level, adopted as zero. We investigate systematically the evolution of deltas for chosen ranges of the discharge $Q\left[\mathrm{~m}^{3} \mathrm{~s}^{-1}\right]$ and the grain size $d[\mathrm{~mm}]$ for approximately 100 days. The value of the discharge is set as constant only at the boundary of the computational domain. The discharge and flow velocity changes in time and space due to local differences in depth and changes in the slope of the deposits. The velocity field is recalculated interchangeably with the sediment transport calculations.

During preliminary calculations we found that this time is enough to build a structure that could be classified. It also indicates that the artificial initial conditions have become not important. The main subject of the investigation is the role of the grain size.

Our research is currently limited to river-dominated deltas without any tides or waves. We neglect their role because of their lower importance in small lakes. To precisely determine the position of our model in the parameter space $(d, Q)$ we assumed that sediments, bed load, and suspended load have monodisperse distribution, i.e. they consist of grains of one size only. It is a typical physical approach where some simplifications are introduced. It corresponds to the situation of well-sorted sediments where one size dominates. Note that in many other considerations the distribution is characterized by one parameter only $-D_{50}$ (e.g., Yalin, 1992: section 1.5). Of course, for a single size of grains there could be a situation when all initially suspended load changes into the bed load (for low velocity and low turbulence). The opposite situation is also possible, i.e. sediments initially included in the bed load are eventually transported as suspended load.
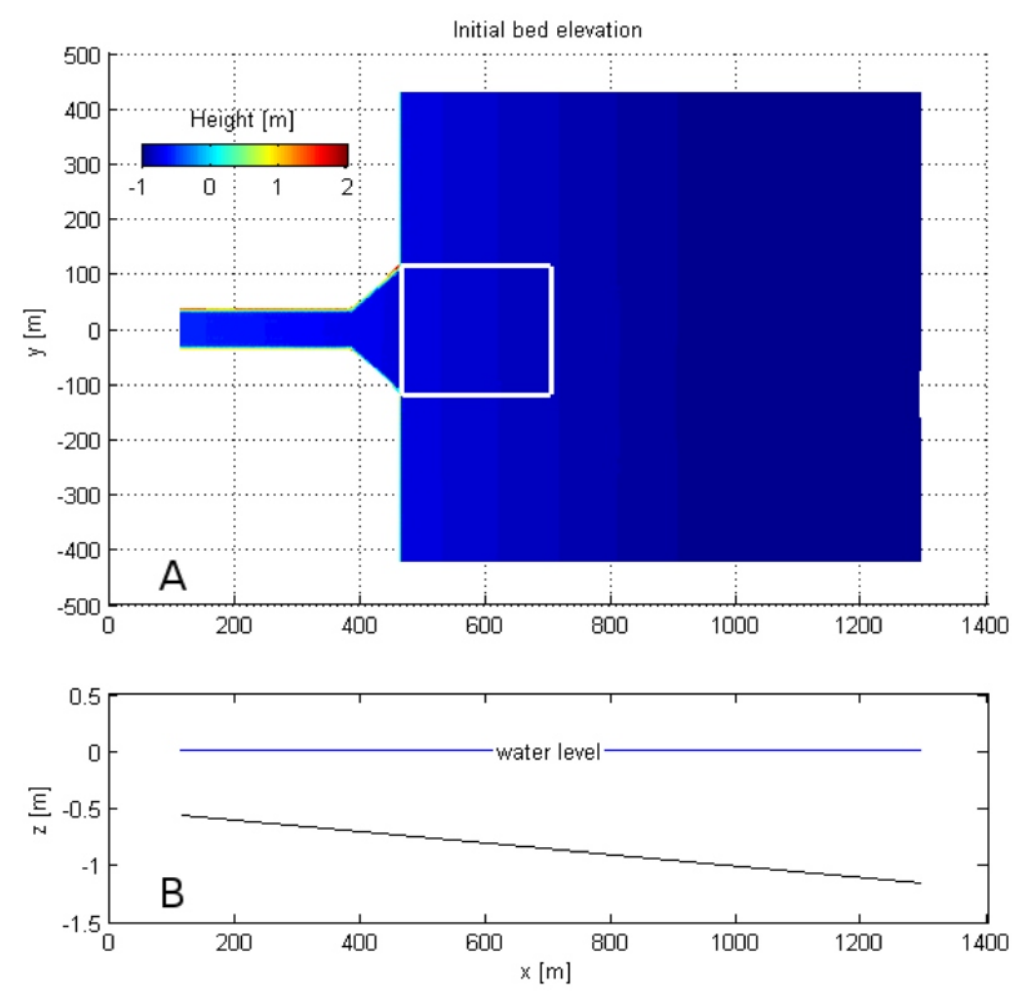

Fig. 1A - initial bed elevation; the white rectangle in the upper panel surrounds the region used for calculations of the average slope for Figure 4; $B-$ the initial vertical cross-section along $y=0$ 
The Manning coefficient is scaled with the grain diameter according to the formula: $n \propto \delta^{1 / 6}$ (Strickler's relation, see e.g., Robert, 2003), therefore:

$$
n=n_{0}\left(\frac{d}{d_{0}}\right)^{1 / 6}
$$

where: $n_{0}=0.3 \mathrm{~m}^{-1 / 3} \mathrm{~s}$ and $d_{0}=0.1 \mathrm{~mm}$ (see also Table 2)

There exists a number of classification schemes for deltas, based on the feeder system, thickness distribution patterns, tectono-physiographic setting, delta front regime etc. (e.g., Nemec, 1990). Our approach utilizes a classification system based on the grain size, slope (see below), and delta-front regime, albeit currently limited to the river-dominated deltas.

For silt-sized grains, cohesion makes erosion more difficult than for sediments without cohesion. However, our finest grains' diameter is $0.05 \mathrm{~mm}$, so cohesion could be neglected according to Soil Survey Division Staff (1993), the sand-silt distinction is made at the $0.05 \mathrm{~mm}$ particle size.

Our research was performed with the CCHE2D package developed by the National Center for Computational Hydroscience and Engineering (Jia and Wang, 2001; Wu, 2001). The numerical model is based on physical equations for the dynamics of flow and additional equations for sediment transport and deposition. It uses the finite elements method. The package is used widely and successfully for practical and theoretical applications (e.g., Magnuszewski and Gutry-Korycka, 2009a, b).

\section{RESULTS}

We performed systematic simulations with both river discharge $Q$ and sediment input at the inflow constant in time. We consider sediments of only one grain size in the whole domain in each test run. The simulations of flow and sediment transport span approximately 100 terrestrial days. The values of the basic parameters are given in Tables 1 and 2. Figures 2-4 present our results. We consider grains of diameters: 0.05 , $0.1,0.5,1.0$, and $10 \mathrm{~mm}$, and discharges at the inflow: 10, 20, 50 and $100 \mathrm{~m}^{3} \mathrm{~s}^{-1}$.

The largest grains $(d=10 \mathrm{~mm})$ build simple deposits inside the river channel and a fan directly in front of it, with very similar shapes for the entire considered range of discharges (Fig. $2 \mathrm{Q}-\mathrm{T}$ ). Similar shapes are formed for grains of diameter $d=0.5$ and $1 \mathrm{~mm}$ under moderate and low discharge, although the slope is lower and there are a few deeper channels, eroded in the deposits due to locally higher flow velocity (cf. panels $\mathrm{K}, \mathrm{L}$, $O$, and $P$ in Fig. 2). The channels deepen and widen with increasing discharge (cf. panels I, J, and $\mathrm{M}-\mathrm{O}$ in Fig. 2). For the smallest considered grains $(0.05 \mathrm{~mm})$ the erosion of the river bed is a dominant process, and deep channels are formed. For large discharges the sediments are pushed away from the mouth of the river, the channels are wider, and the point of bifurcation lies farther from the mouth of the river.

For grains of moderate size we observe the formation of lobate deltaic deposits inside the lake. For $d=0.1 \mathrm{~mm}$ the deposits are very similar in shape as for low discharges (Fig. 2E, F) and their evolution is also similar (see Fig. 3). Under higher discharge, deposits similar in shape can be formed from the grains of a larger diameter (Fig. 2K).

Our model allows us to explore the evolution of the deltaic deposits. The delta slope is determined by the mode of sediment transport and gravity and therefore does not change sig-
Ta ble 1

Basic physical properties of water and sediments in our simulations

\begin{tabular}{|l|c|c|}
\hline Liquid & $\begin{array}{c}\text { Density } \\
\rho\left[\mathrm{kg} \mathrm{m}^{-3}\right]\end{array}$ & $\begin{array}{c}\text { Kinematic viscosity } \\
v\left[\mathrm{~m}^{2} \mathrm{~s}^{-1}\right]\end{array}$ \\
\hline Water & 999.84 & $1.52 \times 10^{-6}$ \\
\hline Sediment & $\begin{array}{c}\text { density } \\
\rho_{\mathrm{s}}\left[\mathrm{kg} \mathrm{m}^{-3}\right]\end{array}$ & $\begin{array}{c}\text { specific gravity } \\
\left(\rho_{\mathrm{s}} / \rho\right) \text { dimensionless }\end{array}$ \\
\hline Quartz & 2650 & 2.650 \\
\hline
\end{tabular}

Table 2

Settling velocities $\omega$, and the Manning coefficient $\boldsymbol{n}$ for grain of diameter $d$

\begin{tabular}{|c|c|c|}
\hline$d[\mathrm{~mm}]$ & $\begin{array}{c}\omega \\
{\left[\mathrm{mm} \mathrm{s}^{-1}\right]}\end{array}$ & $\begin{array}{c}n \\
{\left[\mathrm{~m}^{-1 / 3} \mathrm{~s}\right]}\end{array}$ \\
\hline 0.05 & 1.04 & 0.027 \\
\hline 0.1 & 4.12 & 0.030 \\
\hline 0.5 & 60.7 & 0.039 \\
\hline 1.0 & 113 & 0.044 \\
\hline 10.0 & 418 & 0.065 \\
\hline
\end{tabular}

Base value of $n$ is 0.03 (Geleynse et al., 2010)

nificantly during later stages of development under constant discharge and sediment supply (cf. Fig. 3B, C). The morphological type of the delta (i.e. fan delta or lobate delta) can be determined from the average slope at the early stage of evolution of the deposits.

\section{DISCUSSION}

Our simulations show the expected dependence of the shape of the deposits on the grain size - fine-grained sediments are easily eroded and displaced, but under low discharge form subaqueous delta-like deposits. Sand-sized grains form middle-ground bars and the flow tends to bifurcate; for the coarsest grains the deposits are steep-sloped $\left(S>5 \mathrm{~m} \mathrm{~km}^{-1}\right)$ and take the shape of a fan (Orton and Reading, 1993). We did not observe the formation of an elongated "bird's foot delta" in our simulations. This fact can be attributed to the lack of cohesion of the sediments, which results in faster channel migration and an overall smoother (less branched) shoreline (Hoyal and Sheets, 2009).

We identify three distinct regimes of delta formation processes:

- cases with dominant erosion,

- lobate deltas with low slope,

- fan deltas.

The finest grains can be washed away from the mouth of the river, moved deep into the lake and dispersed over a large area (e.g., Fig. 2A-D). Sand-sized grains are pushed from the channel into the lake, forming lobate deposits elongated along the main course of the flow. The fan deltas are formed for large grains (Fig. 2Q-T). The role of erosion in the region close to the mouth of the river increases with increasing discharge. The sediment grains transported in suspension or as a bed load can be pushed farther into the lake by a water jet with higher momentum. Consequently the three general morphological types described above shift to higher values of diameter, and lobate 


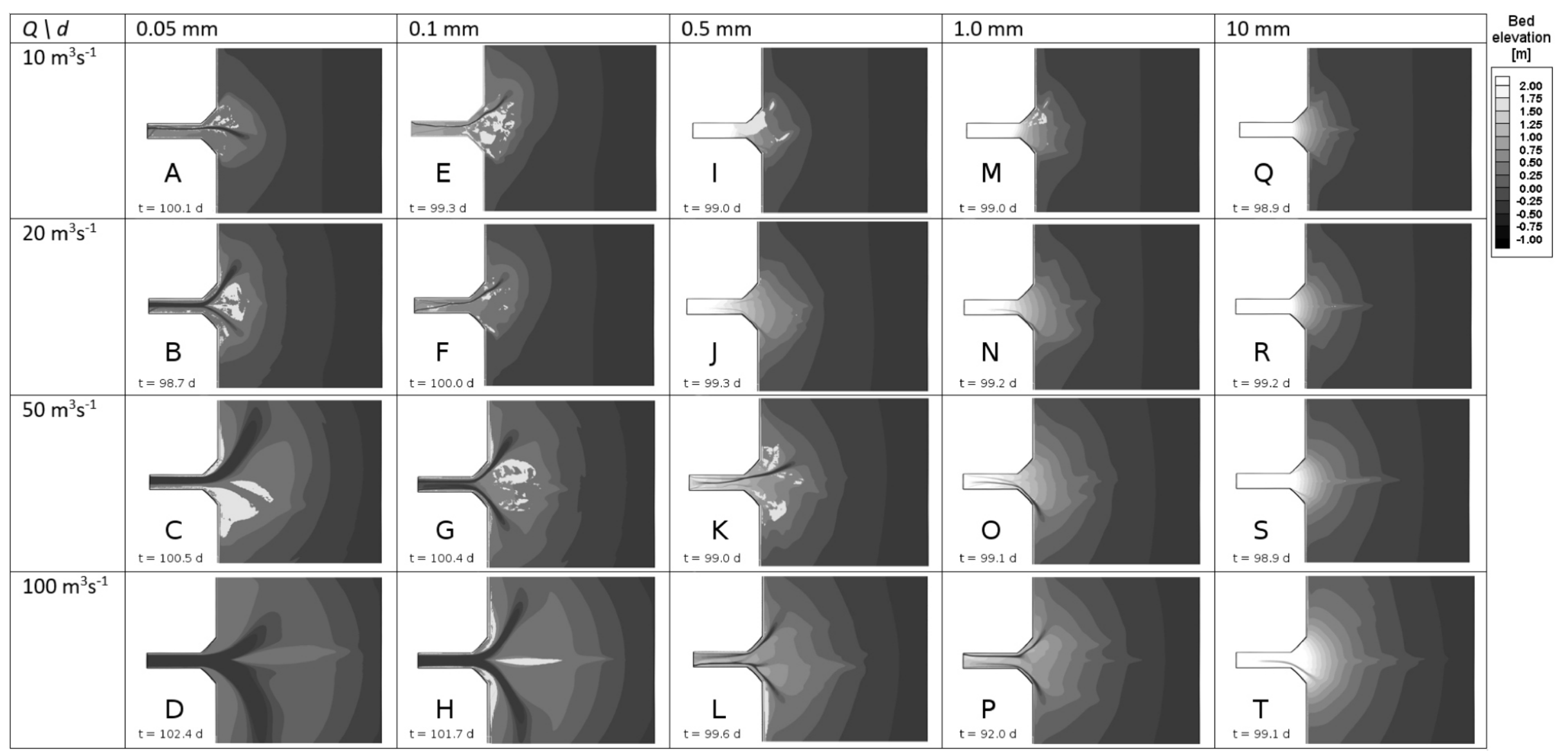

Fig. 2. The bed elevations for considered discharges at the inflow $Q$ and the grain sizes $d$

Simulation times are approximately 100 days in each case; bright patches indicate the dry nodes, where the surface of sedimentary deposits is above the water level 


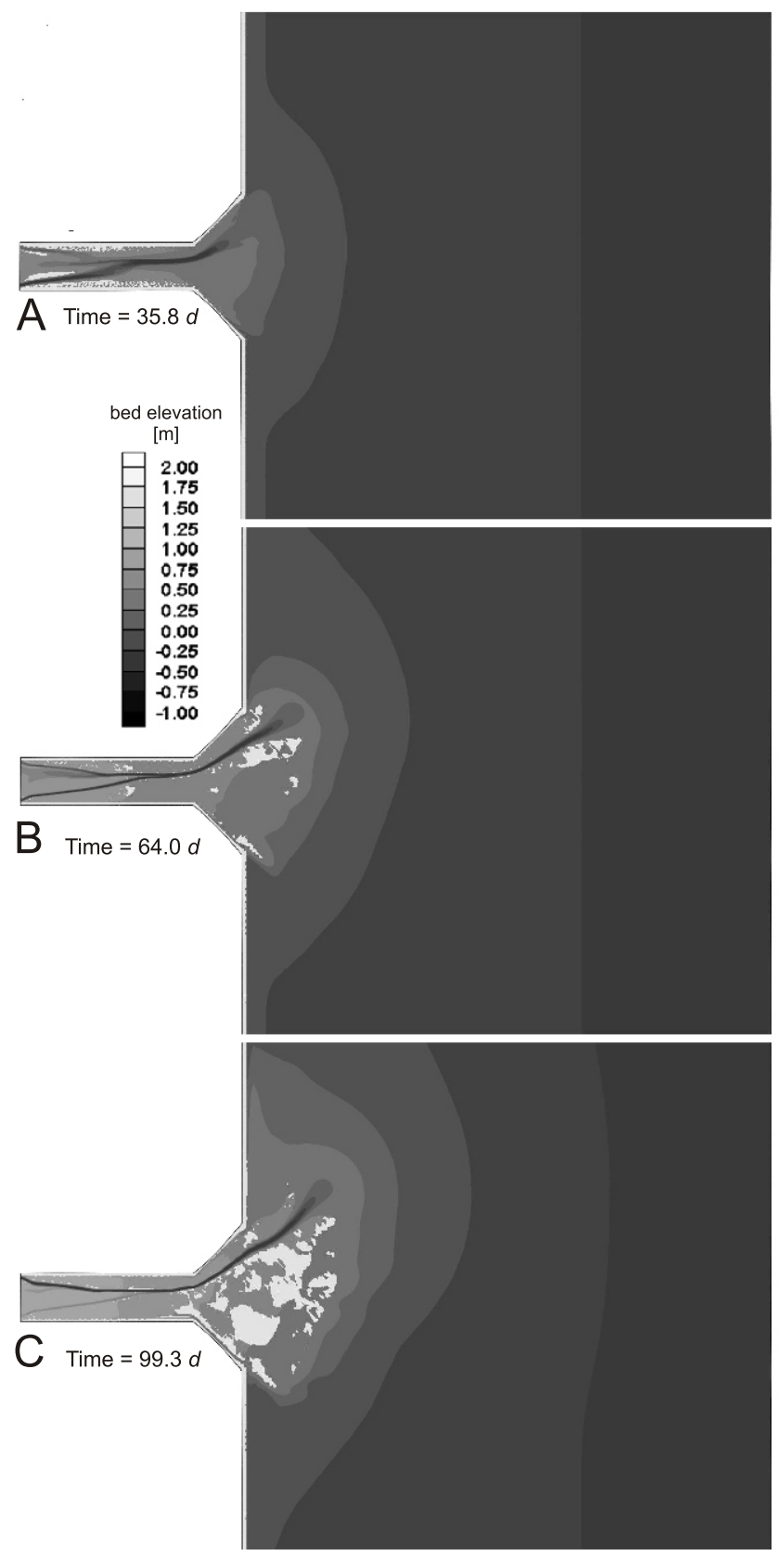

Fig. 3. The evolution of low-lying river delta for $Q=10 \mathrm{~m}^{3} \mathrm{~s}^{-1}, d=0.1 \mathrm{~mm}$

deltas with moderate slope $\left(S=2-3 \mathrm{~m} \mathrm{~km}^{-1}\right)$ can form from larger grains under higher discharge (compare Fig. 2F, K).

The slope of the deposits can be used (in addition to other parameters) to classify the deltas (Nemec, 1990). It is defined as the tangent of the angle of incline of the delta plain, $S=d z / d x$, and it is a dimensionless parameter. We calculated the average slope in the rectangular region enclosed by the white line in Figure 1 and we found that it matches the observable differences in morphology of the deposits. The calculated values of slope are used for Figure 4, where contours of constant slope are given in $(d, Q)$ parameter space. There are three distinct regions, denoted in the figure as: fan deltas, lobate deltas, washing out, so the figure confirms that the morphological type of delta can be related to the average slope. Note that this slope is a result of evolution of the deposits and it changes in time at a given location (starting from an initial condition given in Fig. 1) due to processes of sedimentation and erosion.

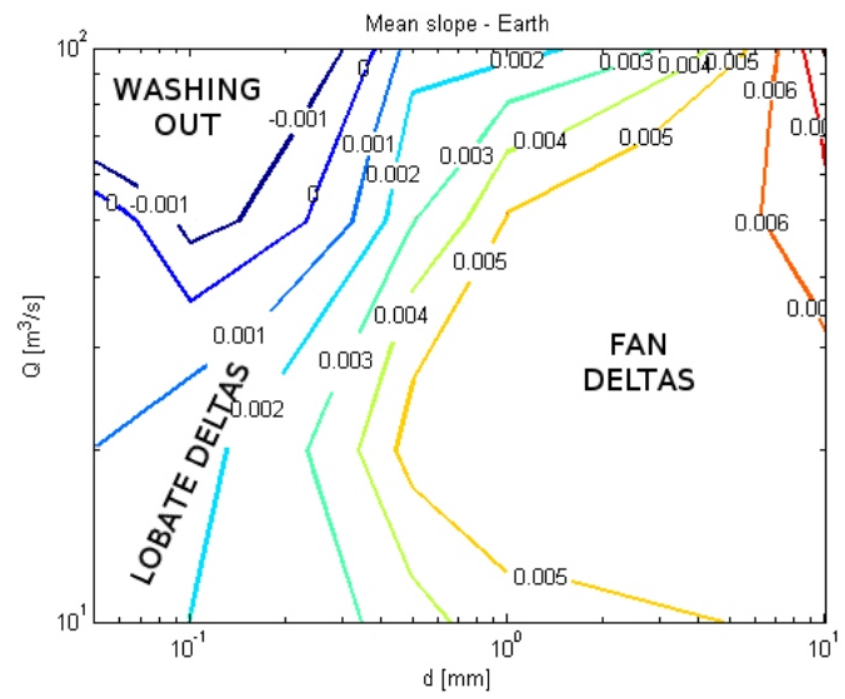

Fig. 4. The contours of the mean bed slope (averaged over the rectangular region given by the white line in Figure 1) as a function of grain size $d$ and discharge $Q$

For the presented ranges of $Q$ and $d$, three types of morphologies of the deposits are found

In some simulations, for large values of discharge and small diameters, a clear bifurcation of the flow is visible. The distance to the middle-ground bar from the inlet grows with the river discharge (compare Fig. 2G, H). In some cases during the evolution, the main place of deposition moves from one side of the outlet to the other (e.g., Fig. 2C). This process is also observed in the real rivers, where channel switching occurs, sometimes leading to the abandonment of the entire delta lobe, as well as in the simulations of large river deltas by other authors (e.g., Seybold et al., 2007).

\section{SUMMARY}

Our model successfully reproduces the expected dependence of morphology of the deposits on the grain size and the discharge. We observed the bifurcation of the flow and switching of the place of deposition similar to phenomena observed in real terrestrial rivers.

We identified three regions in the $(d, Q)$ parameter space that correspond to dominance of erosion, the formation of lobate deltas, and fan deltas, respectively.

For small rivers the deposits formed by the steady flow can be characterized by the average delta slope in the early stage of the evolution of a delta.

We plan to extend our numerical simulations for time-dependent discharge (corresponding to changes of the rainfall) on Earth and on Titan, 3D models and investigation of the possible role of the tides and waves. In the framework of the Extraterrestrial Rivers Modeling Group we are developing laboratory facilities for modelling the rivers. Theoretical research is also continued. Especially, we want to express our conclusions in the form of dimensionless numbers.

Acknowledgements. This research was performed in the framework of the Extraterrestrial Rivers Modeling Group at the University of Warsaw. We are grateful to Prof. A. Wysocka from the Faculty of Geology at the University of Warsaw. We also thank N. Zalewska and the anonymous reviewers for their comments and suggestions. 


\section{REFERENCES}

Anderson, R.P., Anderson, S.P., 2010. Geomorphology: the Mechanics and Chemistry of Landscapes. Cambridge University Press.

Edmonds, D.A., Slingerland, R.L., 2007. Mechanics of river mouth bar formation: implications for the morphodynamics of delta distributary networks. Journal of Geophysical Research: Earth Surface (2003-2012), 112 (F2).

Galloway, W.E., 1975. Process framework for describing the morphologic and stratigraphic evolution of deltaic depositional systems. In: Deltas: Models for Exploration (ed. M.L. Broussard): 87-98. Houston Geological Society.

Geleynse, N., Storms, J.E.A., Stive, M.J.F., Jagers, H.R.A., Walstra, D.J.R., 2010. Modeling of a mixed-load fluvio-deltaic system. Geophysical Research Letters, 37: L05402.

Hoyal, D.C.J.D., Sheets, B.A., 2009. Morphodynamic evolution of experimental cohesive deltas. Journal of Geophysical Research: Earth Surface, 114 (F2).

Irwin, R.P., Howard, A.D., Craddock, R.A., Moore, J.M., 2005. An intense terminal epoch of widespread fluvial activity on early Mars: 2. Increased runoff and paleolake development. Journal of Geophysical Research, 110: E12S15.

Jia, Y., Wang S., 2001. CCHE2D: Two-dimensional Hydrodynamic and Sediment Transport Model for Unsteady Open Channel Flow Over Loose Bed. Technical Report no. NCCHE-TR2001-1.

Kereszturi, A., 2010. Lakes beyond the Earth: dry lakebeds on Mars, and active methane-ethane lakes on Titan. In: Ponds: Formation, Characteristics, and Uses (ed. P.L. Meyer): 125-138. Nova Publisher.

Kondolf, G.M., Piégay, H., 2016. Tools in Fluvial Geomorphology. John Wiley and Sons.

Magnuszewski, A., Gutry-Korycka, M., 2009a. Reconstruction of the Vistula River extreme floods passage through the city of
Warsaw in natural river conditions (in Polish with English summary). Prace i Studia Geograficzne, 43: 141-151.

Magnuszewski, A., Gutry-Korycka, M., 2009b. Flood waters flow in the contemporary Vistula River channel (in Polish with English summary). Prace i Studia Geograficzne, 43: 153-162.

Medvedev, I.P., Rabinovich, A.B., Kulikov, E.A., 2013. Tidal oscillations in the Baltic Sea. Oceanology, 53: 526-538.

Misiura, K., Czechowski, L., 2015. Numerical modelling of sedimentary structures in rivers on Earth and Titan. Geological Quarterly, 59 (3): 565-580.

Nemec, W., 1990. Deltas - remarks on terminology and classification. IAS Special Publications, 10: 3-12.

Orton, G.J., Reading, H.G., 1993. Variability of deltaic processes in terms of sediment supply, with particular emphasis on grain size. Sedimentology, 40: 475-512.

Robert, A., 2003. River Processes: an Introduction to Fluvial Dynamics. Hooder Education, London, UK.

Seybold, H., Andrade, J.S., Herrmann, H.J., 2007. Modeling river delta formation. PNAS, 104: 16804-16809.

Soil Survey Division Staff, 1993. Soil survey manual. Soil Conservation Service. U.S. Department of Agriculture Handbook, 18.

Trebitz, A.S., 2006. Characterizing seiche and tide-driven daily water level fluctuations affecting coastal ecosystems of the Great Lakes. Journal of the Great Lakes Research, 32: 102-116.

Witek, P.P., Czechowski, L., 2015. Dynamical modelling of river deltas on Titan and Earth. Planetary and Space Science, 105: 65-79.

Wu, W., 2001. CCHE2D Sediment Transport Model (Version 2.1). Technical Report no. NCCHE-TR-2001-3.

Yalin, M.S., 1992. River Mechanics. Pergamon Press. 